\title{
The legacy of G. N. Ramachandran and the development of structural biology in India*
}

\author{
M. Vijayan ${ }^{\dagger}$ \\ Molecular Biophysics Unit, Indian Institute of Science, Bengaluru 560 012, India
}

\begin{abstract}
G. N. Ramachandran is among the founding fathers of structural molecular biology. He made pioneering contributions in computational biology, modelling and what we now call bioinformatics. The triple helical coiled coil structure of collagen proposed by him forms the basis of much of collagen research at the molecular level. The Ramachandran map remains the simplest descriptor and tool for validation of protein structures. He has left his imprint on almost all aspects of biomolecular conformation. His contributions in the area of theoretical crystallography have been outstanding. His legacy has provided inspiration for the further development of structural biology in India. After a pause, computational biology and bioinformatics are in a resurgent phase. One of the two schools established by Ramachandran pioneered the development of macromolecular crystallography, which has now grown into an important component of modern biological research in India. Macromolecular NMR studies in the country are presently gathering momentum. Structural biology in India is now poised to again approach heights of the kind that Ramachandran conquered more than a generation ago.
\end{abstract}

\section{Introduction}

THE nineteen fifties marked the beginning of the heroic age of structural molecular biology. Although perceptive leaders of science like J. D. Bernal and W. T. Astbury and their younger colleagues Dorothy (Crowfoot) Hodgkin and Max Perutz initiated biological macromolecular structural studies earlier than that, substantive results began to appear only in the fifties. The discovery of the $\alpha$ helix and the $\beta$-sheet through simple modelling, published in 1951, constituted a major advance in structural studies on proteins. This was soon followed by the proposal of the double-helical model of DNA by Watson and Crick in 1953, a proposal that revolutionized modern biology. During the same period, Perutz and his colleagues demonstrated the feasibility of using the multiple isomorphous replacement for solving protein structures by X-ray crystallography. This eventually led to

\footnotetext{
*Reproduced with permission from Biomolecular Forms and Functions: A Celebration of 50 years of the Ramachandran Map (eds Manju Bansal and N. Srinivasan), 2013, IISc-WSPC.

†e-mail: mv@mbu.iisc.ernet.in
}

spectacular advances in macromolecular crystallography, which is central to structural biology and, indeed, modern biology as a whole. It was during this period when pathbreaking results were emanating from leading centres like the MRC Laboratory at Cambridge, UK and Caltech, USA that G. N. Ramachandran, often known as GNR, burst onto the scene from a remote, comparatively obscure laboratory at Madras (now Chennai). GNR rose to become a pioneer and global leader in molecular modelling, computational biology and what we now call bioinformatics. He also made outstanding contributions to theoretical crystallography. Furthermore, his efforts provided much of the inspiration for the further development of structural biology in India, which now encompasses experimental approaches like crystallography and NMR as well.

\section{The prelude: Bangalore to Madras}

Educated at Ernakulam in Kerala and Trichy in Tamil Nadu, GNR joined the Physics Department of the Indian Institute of Science, Bangalore in 1942 as a research student of C. V. Raman. He obtained his M Sc and D Sc degrees working on the optics of heterogeneous media, and X-ray topography and diffraction. He then proceeded to England in 1947 on an 1851 Exhibition Scholarship to work with W. A. Wooster in the Cavendish Laboratory at Cambridge, then headed by W. L. Bragg. The laboratory was then at the threshold of major advances in structural biology involving Max Perutz, John Kendrew and others with inspiration from Bragg. Ironically, there is no evidence of GNR, who himself subsequently became a pioneer in the area, having had any significant scientific interaction with them. He worked primarily on the determination of elastic constants using diffuse scattering, for which he was awarded the Ph D degree of the Cambridge University in 1949. He returned to the Physics Department of the Indian Institute of Science during the same year and established an X-ray crystallography laboratory there with the help of Gopinath Kartha and others.

The legendary Lakshmanaswamy Mudaliar was then the Vice-Chancellor of the Madras University, one of the three oldest modern Universities of India. On his invitation, based on a recommendation of C. V. Raman, GNR joined the University in 1952 as the founder-head of the 

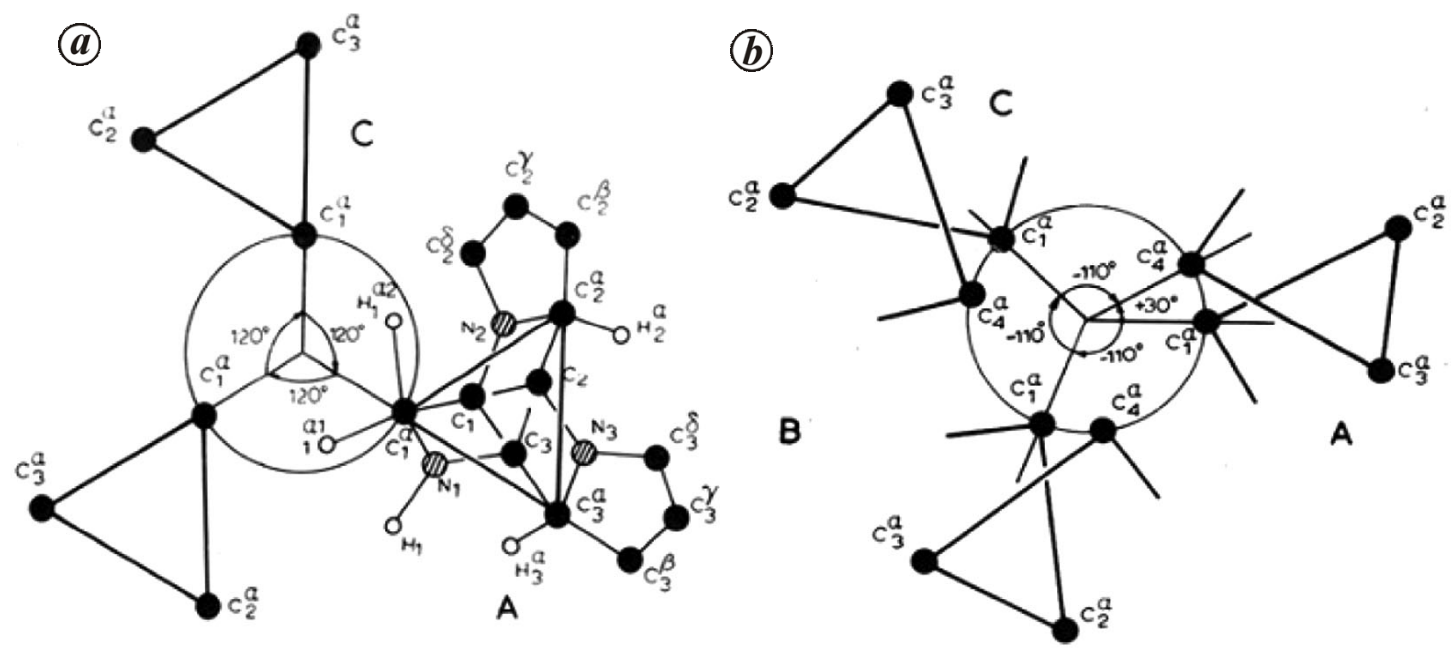

Figure 1. $\boldsymbol{a}$, The first approximation to the triple helical model of collagen proposed by Ramachandran and Kartha. $\boldsymbol{b}$, The modified coiled-coil model. This figure and Figure 6 have been reproduced with permission from the doctoral thesis of Manju Bansal ${ }^{60}$.

Department of Physics. That marked the beginning of an extraordinary productive period in Ramachandran's career. Mudaliar and Ramachandran had a unique relationship. Mudaliar provided all the administrative and financial support. Ramachandran's mandate was to produce world-class science, unencumbered by excessive bureaucratic or financial constraints.

\section{Collagen, Ramachandran map, other conformational studies}

While Ramachandran was looking for important problems to work on in his newly established laboratory, it was J. D. Bernal, then on a visit to Madras, who suggested that he might look at the structure of collagen. The structures of the other two classes of fibrous proteins and indeed that of DNA, had been essentially solved. The structure of collagen remained unsolved, despite the efforts of many leading scientists of the time. Following the suggestion of Bernal, Ramachandran and his associate Kartha initiated fibre diffraction and modelling studies on collagen. Using all the relevant information available at that time, they proposed in 1954 a first approximation to their model consisting of three left-handed threefold helical polypeptide chains arranged at the apices of an equilateral triangle ${ }^{1}$ (note 1) (Figure $1 a$ ). It was known that a third of collagen sequence is made up of glycines, the smallest of the 20 naturally occurring amino acids. From this information, Ramachandran and Kartha made the assumption that every third residue in the polypeptide chain was a glycine. In their model, the glycines occurred at the interface of the three helices. The model did not have any intra-chain hydrogen bonds. The hydrogen bonds were between chains. The proposed model, however, was not entirely compatible with the fibre pattern of collagen and was therefore modified ${ }^{2}$. The modified model, which was wholly compatible with the pattern, involved the coiling of the three helices, now with 3.3 residues per turn, around a common axis (Figure $1 b$ ). This coiledcoil model of collagen (Figure 2) has been widely accepted.

The coiled-coil model of collagen, proposed by Ramachandran and Kartha, involved two hydrogen bonds per turn between adjacent chains. Francis Crick and Alex Rich suggested that only one such hydrogen bond is possible as two would lead to unacceptable steric contacts. The somewhat acrimonious debate on the two hydrogen bonds and the one hydrogen bond models led Ramachandran and his colleagues to critically examine the minimum interatomic distances between non-bonded atoms using all the available relevant crystal structures as the database. It turned out that two non-bonded atoms can come substantially closer than the sum of their van der Waals radii. Based on the data, they arrived at two minimum limiting distances for each type of non-bonded interatomic distance, the normal limit that usually occurs and the extreme limit that is sometimes possible. As the main chain of a polypeptide can be considered as a series of planar peptide units hinged at $\mathrm{C}^{\alpha}$ positions, they also realized that the conformation of the chain can be described by two rotation angles each, which we now call $\phi$ and $\psi$, about the single bonds that hinge at $\mathrm{C}^{\alpha}$ positions (Figure 3). Using the limiting distances mentioned above, Ramachandran, Ramakrishnan and Sasisekharan worked out the allowed ranges of $\phi$ and $\psi$ angles for an alanyl dipeptide. The two-dimensional representation of the allowed ranges for the two torsion angles came to be known as the Ramachadran map ${ }^{3}$. The allowed regions are obviously much broader for the glycyl residue. The Ramachandran map, devised from first principles at the infancy 
of protein crystallography, remains the simplest descriptor and tool for validation of protein structures (Figure 4).

The computational efforts of Ramachandran at the Madras University encompassed many aspects of biomolecular conformation ${ }^{4}$, although those on collagen and the Ramachandran map are the best known among them. He initiated computational studies on polysaccharide conformation $^{5}$. His work on homopolypeptides is well known. It is interesting to note that he invoked C-H---O hydrogen bonds as early as in 1966 in a model of polyglycine $^{6}$ (Figure 5). His contributions to the understanding of hydrogen bonds, made in collaboration with Chidambaram are well-recognized ${ }^{7}$.
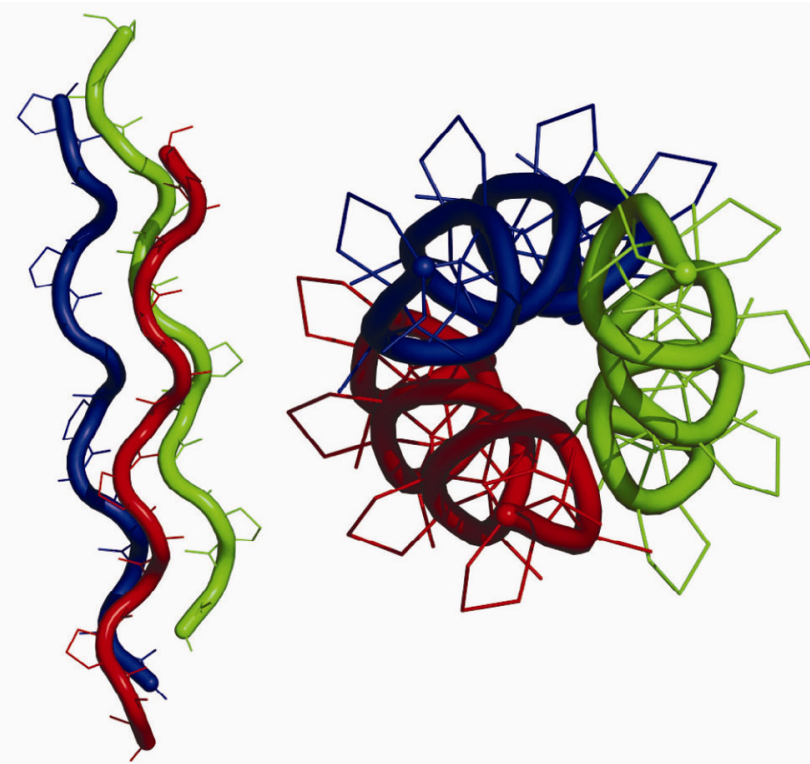

Figure 2. Perpendicular views of four turns of the collagen structure in cartoon representation. This figure and Figure 5 were generated using Pymol ${ }^{61}$.

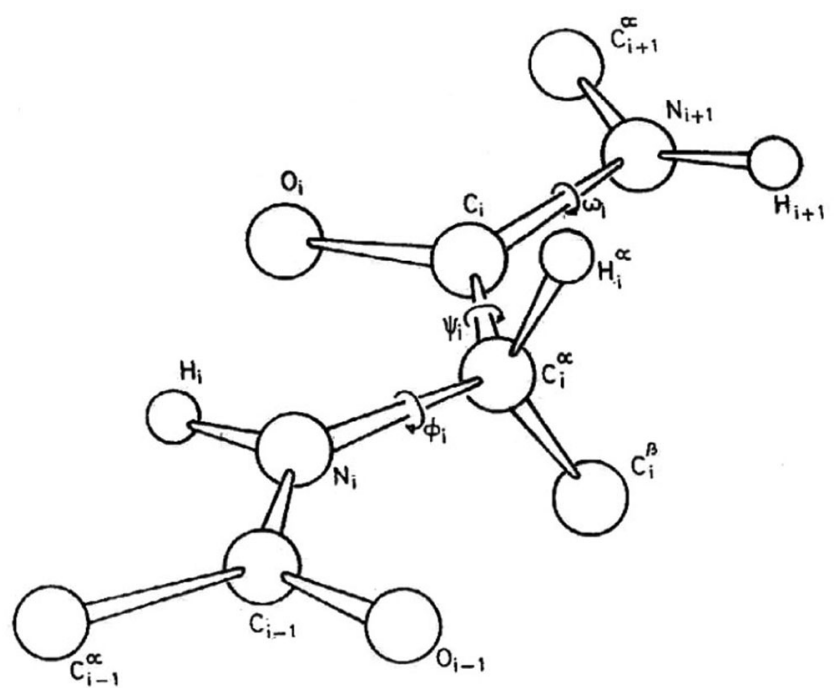

Figure 3. Two planar trans peptide units hinged at the $i$ th $\alpha$-carbon atom. $\phi_{i}$ and $\psi_{i}$ are indicated. Reproduced with permission from Ramakrishnan $^{62}$

\section{Crystallographic methodology}

Ramachandran has been recognized as an outstanding crystallographer. He has many achievements to his credit in experimental crystallography, but his most important contributions have been in theoretical crystallography. Along with his colleagues, S. Raman and others, Ramachandran worked extensively on the use of anomalous

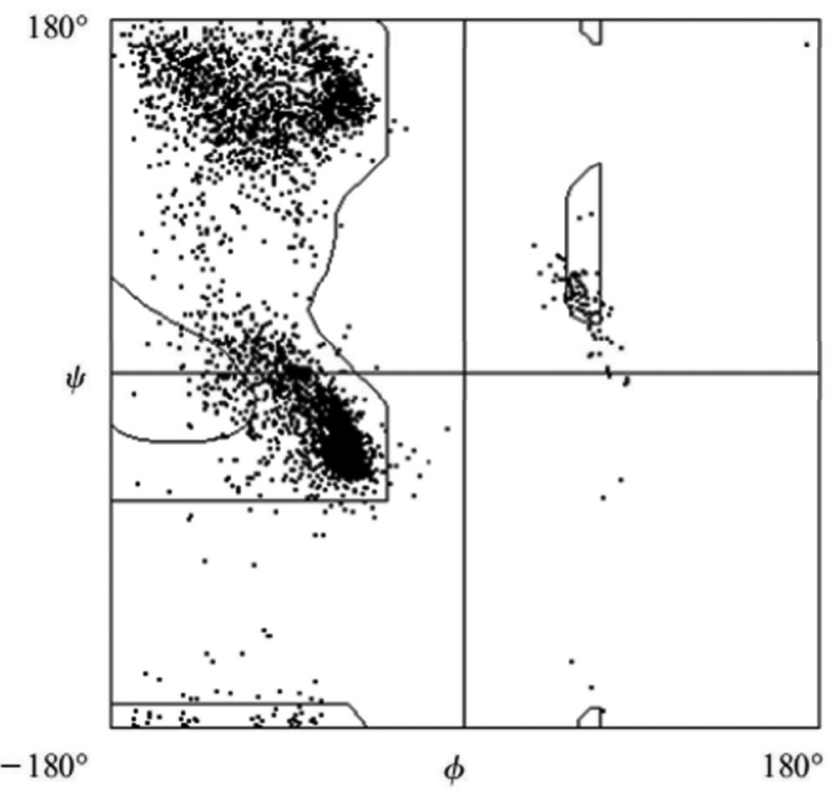

Figure 4. Ramachandran map generated from 21 selected highresolution structures. Open circles correspond to glycine residues. Reproduced with permission from Vijayan and Johnson ${ }^{63}$.

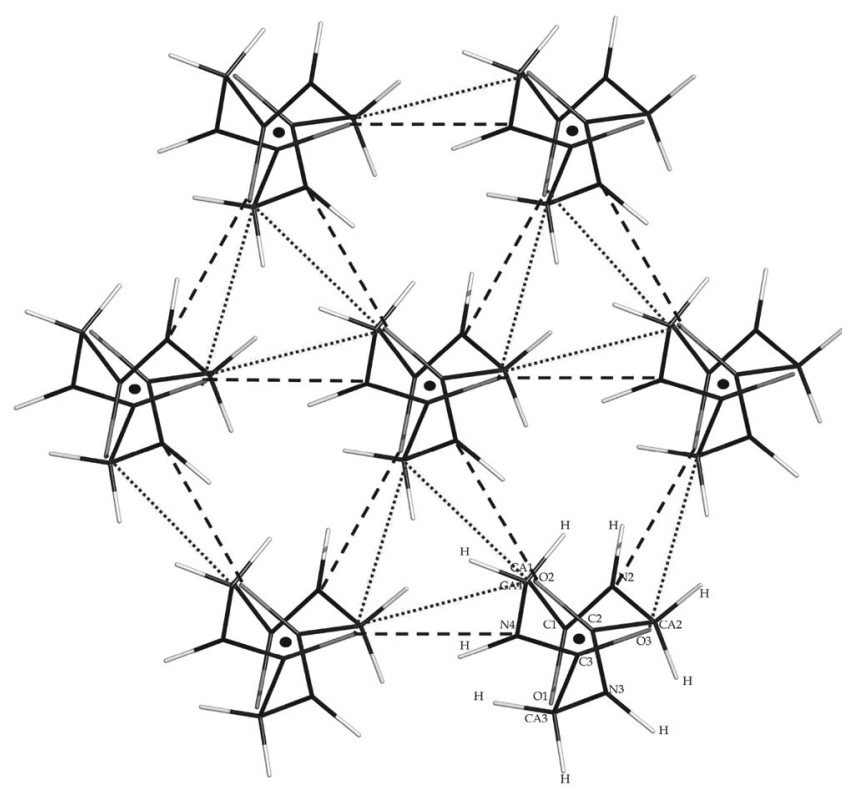

Figure 5. Model of the structure of polyglycine. N-H... $\mathrm{C}-\mathrm{H}$... O hydrogen bonds are represented by dashed and dotted lines respectively. 


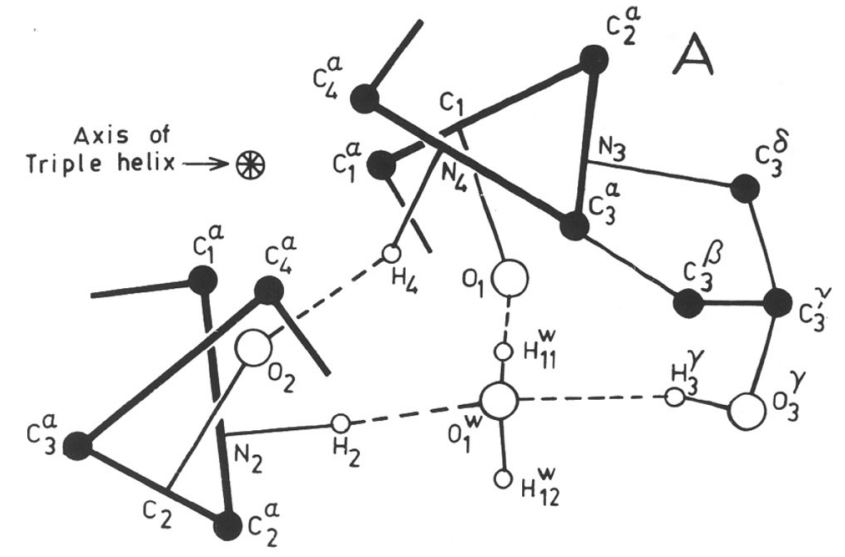

Figure 6. The proposed role of hydroxyproline in collagen involving a water bridge between adjacent helices.

dispersion in phase determination ${ }^{8,9}$. The methods developed by them have been used widely. He initiated and participated in, notably with R. Srinivasan and S. Parthasarathy, studies on crystallographic statistics ${ }^{10,11}$. The contributions of Ramachandran, Srinivasan and their colleagues concerned with Fourier transforms in crystallography have been outstanding ${ }^{12,13}$. In addition to applications, they illuminated the theoretical foundation of crystallography.

\section{Back to Bangalore}

Ramachandran found it difficult to adjust to the ambience that developed at the Madras University after the retirement of Lakshmanaswami Mudaliar. He left Madras in 1970 and joined the Indian Institute of Science, Bangalore in 1971, after a year-long sojourn at Chicago. He established a vibrant school in the form of the Molecular Biophysics Unit at the Institute. His own personal research at Bangalore was by and large a continuation of the Madras efforts. During the transition period from Madras to Bangalore via Chicago, he completed some path-breaking work on image reconstruction using convolutions ${ }^{14}$. Another issue he addressed was the nonplanarity of the peptide group ${ }^{15}$. His work on the conformation of peptides containing L- and D-residues turned out to be of considerable importance in relation to peptide antibiotics ${ }^{16}$. As a fitting finale to his illustrious career in structural biology, which started with the proposal of the coiled-coil structure of collagen, the last pieces of his original research in the area were primarily concerned with this fibrous protein. In particular, he and his last graduate student Manju Bansal worked on the role of hydroxyproline, the non-standard amino acid that occurs in collagen ${ }^{17}$. Its main role appeared to be the formation of a water bridge between adjacent chains (Figure 6).

This observation was interesting in relation to the earlier controversy on the number of hydrogen bonds between adjacent chains of the triple helix. It appeared that there could be one direct hydrogen bond and one water-mediated interaction between adjacent chains. Subsequently, many crystal structures incorporating collagenlike and natural collagen sequences became available. These structures lent further confirmation to the Ramachandran model of collagen, including water bridges.

\section{The immediate aftermath}

Many former students and colleagues of Ramachandran had already been established as leaders in the area even during the time he was active. They carried forward the efforts after the withdrawal of Ramachandran from the scene. A notable result to emerge during the late seventies and the early eighties was concerned with the variability in the structure of DNA. The concept of DNA as a monotonic helix was challenged by V. Sasisekharan and his colleagues ${ }^{18-20}$. They were the first to open up the debate on the structure of DNA, despite considerable resistance from many quarters. We now routinely discuss secondary structural features of DNA and their role in transcription. This aspect was also addressed as a follow up of theoretical investigations ${ }^{21,22}$. The computational work on DNA was carried forward by others ${ }^{23-26}$. The systematics of saccharide conformation were developed by V. S. R. $\mathrm{Rao}^{27-29}$. The work of C. Ramakrishnan on cyclic peptides ${ }^{30}$ and hydrogen bonds ${ }^{31}$ also deserves special mention. Indians were among the first to make use of the three-dimensional structures of proteins for bioinformatics analysis after the Protein Data Bank was established in the early seventies. Those who then effectively used the data included R. Srinivasan of the Madras University $^{32,33}$, to start with, among others ${ }^{34-37}$. Substantial progress was made during this phase in the crystallography of amino acids and peptides ${ }^{38-43}$, including the relevance of their supramolecular association to chemical evolution and origin of life ${ }^{44}$, nucleic acids and their constituents $^{45}$, ionophores and related compounds ${ }^{46,47}$, and medicinally important molecules ${ }^{48-50}$. The same is true about NMR studies on medium-sized biomolecules ${ }^{51-53}$. The period also witnessed the beginnings of macromolecular crystallographic studies in India ${ }^{54-59}$.

\section{Computational efforts: a pause and the resurgence}

By the mid eighties, the strength of computational biology in India apparently began to wane. By then the area became highly compute-intensive. India did not produce computers. Most of the time the country was under different kinds of sanctions and there were severe restrictions on supply of computers to India by the developed countries. Inadequate computational facilities thus became a major handicap. Computational biology also 
became highly data-based. Data-based operations thrive in an ambience where experimental data are produced in the same neighbourhood. India did not then produce much experimental data and this again proved to be a handicap. Happily, both these problems no longer exist. Computers are now universally available and a strong macromolecular crystallographic activity, spread over dozens of centres, has emerged in India. Macromolecular NMR studies are in a phase of expansion. Though late in starting, genome sequencing is also in progress at several centres of India. These developments have helped in a resurgence of computational biology and bioinformatics in the country.

The resurgence referred to above encompasses several groups and leaders. The work includes software development, construction of databases and research pertaining to different biomolecules and their assemblies. The trend has been to carry out experimental and computational work in tandem, often by the same group. Much of the effort has been based on individual initiative, but conscious organized efforts also played a major role in the further development of the area. As an act of great foresight, a highly networked bioinformatics activity was initiated in 1987 by the Department of Biotechnology soon after the Department was established in 1986. This network continues to be the backbone of the efforts in the area in the country. Among the more recent initiatives, the coordinated activities at the Institute of Genomics and Integrative Biology (IGIB), particularly those related to the Open Source Drug Discovery (OSDD) programme of the Council of Scientific and Industrial Research (CSIR), merit special mention.

\section{Macromolecular crystallography}

India has a distinguished tradition in X-ray crystallography going back to the thirties of the last century. The theoretical contributions of G. N. Ramachandran from the fifties onwards have already been referred to. The Indian effort in small molecule crystallography encompassed a wide spectrum involving amino acids and peptides, nucleic acid components, medicinally important molecules, ionophores and related compounds, supramolecular assembly and peptide design. A few Indians have been involved in macromolecular crystallography projects abroad, notably Gopinath Kartha, who led the structure solution of ribonuclease A. However, I was the first trained protein crystallographer to return to India in 1971, after participating in the structure solution of insulin in Dorothy Hodgkin's laboratory at Oxford. The general ambience, including the funding situation, was not propitious then for initiating macromolecular crystallography in the country. Therefore, the thrust of my early independent efforts at the Indian Institute of Science, Bangalore was on crystalline complexes involving amino acids and peptides, and their relevance to supramolecular association in general and chemical evolution and origin of life in particular. In the meantime, K. K. Kannan, who was involved in the structure solution of carbonic anhydrase at Uppsala, joined the Bhabha Atomic Research Centre, Bombay in 1978.

Macromolecular crystallography in India received the first major impetus when the Department of Science \& Technology (DST) handsomely funded our group at Bangalore under their newly initiated Thrust Area Programme. The Bangalore centre was also mandated to function as a national nucleus for the development of the area in the country. Since then, work in the area has spread across the country and is now being pursued in about 30 institutions in India (Figure 7). In addition to DST, agencies like the Department of Biotechnology (DBT) and the Council of Scientific and Industrial Research (CSIR) have also been generously supporting the effort.

Much of the early efforts centered around lectins, protein hydration, plant viruses and carbonic anhydrase. In particular, the work on lectins, started at a time when the role of protein-sugar interactions in biological recognition was beginning to move into focus, has had considerable impact on the early development of macromolecular crystallography in the country, including manpower training. In addition to the areas mentioned above, the current activities in macromolecular crystallography in the country encompass several widely different systems. Particularly noteworthy is the work on proteins present in different body fluids. Proteins involved in inflammation and design of their inhibitors constitute an important area of study. Another effort involves exploration of molecular mimicry and its extension to fundamental immunological processes like antibody maturation. Proteases and their inhibitors are studied in several laboratories. Another exciting systematic effort involves proteins engaged in editing during amino acid incorporation in peptide synthesis. Other systems being investigated include membrane proteins, ureases and transcription factors. Quite apart from the work on proteins, efforts are also underway to explore the sequence dependence of DNA structure.

Infectious diseases are of particular interest to a developing country like India. Therefore, a programme of structural biology of microbial pathogens was orchestrated around the turn of the century. The most successful component of the programme has been that on mycobacterial proteins, with special emphasis on TB proteins. As of now, ten institutions participate in the concerted structural effort on these proteins. The proteins studied include those involved in DNA replication, recombination, repair and modification; transcription and translation; amino acid synthesis, degradation and modification; fatty acid, mycolic acid and peptidoglycan synthesis; biosynthesis of cofactors, prosthetic groups and carriers; and signalling. Work is underway on chaperones/heat shock proteins and 


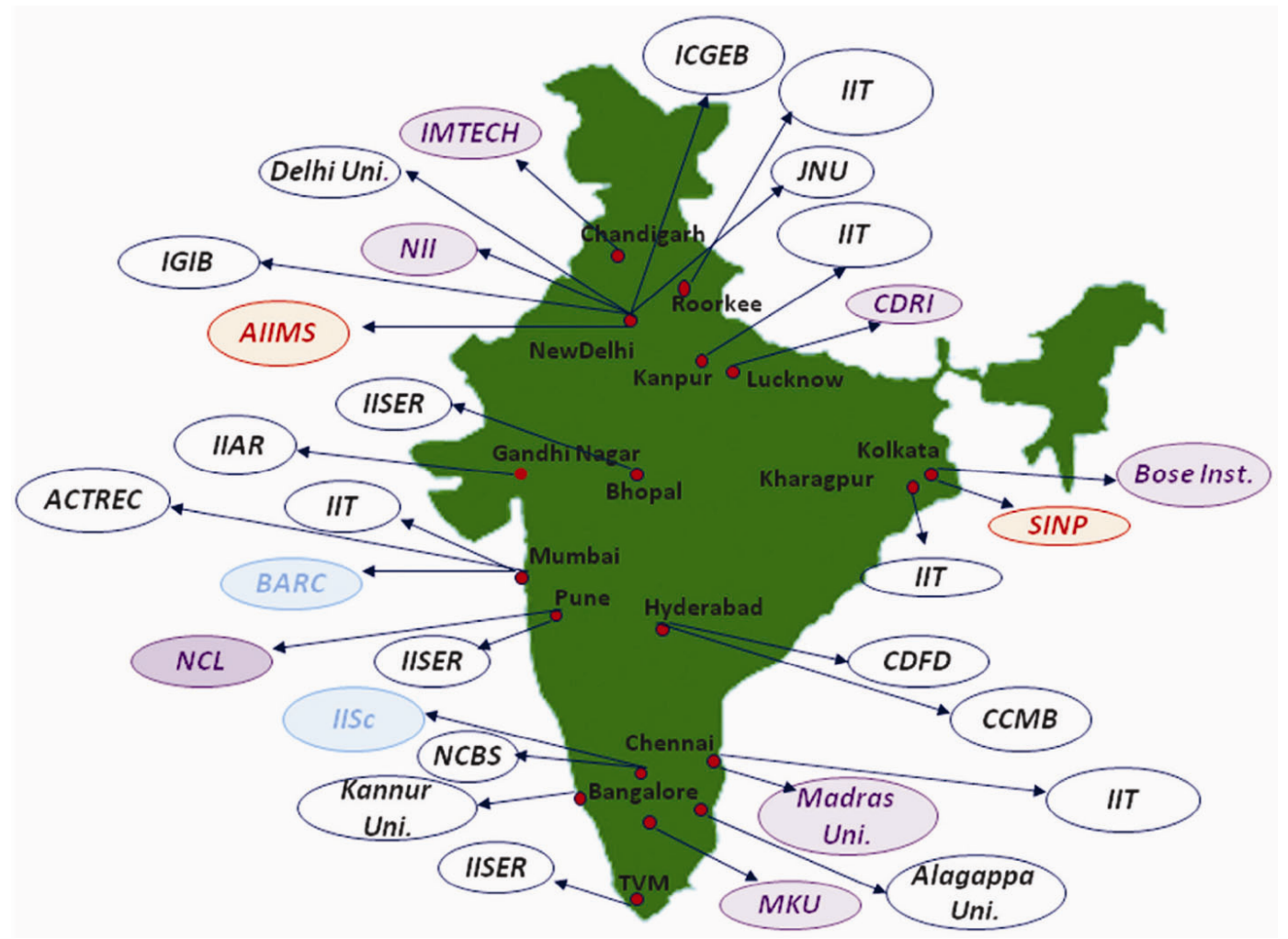

Figure 7. Institutions where macromolecular crystallographic studies were initiated before 1981 (sky blue), during 1981-91 (red), 1991-2001 (purple) and from 2001 till date (black).

toxin-antitoxin systems as well. In fact, more than $10 \%$ of the Mycobacterium tuberculosis proteins of known structure have been X-ray analysed in Indian laboratories. Another bacterium, the proteins of which are being analysed in more than one laboratory is Salmonella typhimurium. Work on proteins from malarial parasites, particularly those involved in sexual development and fatty acid synthesis, is in progress in a couple of laboratories. Structural studies are underway on proteins form Leishmania donovani and Entamoeba histolytica as well. The work on plant viruses, though not directly relevant to human diseases, has provided a wealth of information of general interest on virus assembly. Another interesting piece of work currently underway involves a tethered mutant of the HIV protease. In addition to their importance in elucidating the biology of the concerned organisms, structural studies on proteins from microbial pathogens, particularly TB proteins, now provide a platform for structure-based inhibitor design in the country.

\section{Macromolecular NMR studies}

Ramachandran himself was involved in setting up a major Fourier transform NMR facility, a $270 \mathrm{MHz}$ machine, at the Indian Institute of Science, Bangalore under the leadership of C. L. Khetrapal and Anil Kumar. Almost in parallel, serious NMR studies developed through the efforts of G. Govil and his colleagues at the Tata Institute of Fundamental Research, Mumbai as well. Both the groups have been deeply involved in the development of NMR methodology. Much of the early efforts centered around the two institutions have been on oligopeptides and oligonucleotides.

NMR facilities are now available in several institutions in the country. However, macromolecular structural studies are largely confined to the two centres mentioned above and the Central Drug Research Institute (CDRI), Lucknow. Such studies are now in the offing in a few other institutions. The proteins studied so far in India using NMR include calcium-binding proteins, barstar, ubiquitin, toxins and proteins from mycobacteria, Leishmania donovani and the malarial parasite. An effort concerning the self-assembly process of GTPase effector domain of dynamin is also noteworthy. Although not directly relevant to structural biology, MRI and wholebody NMR form a vibrant component of the NMR efforts in the country.

\section{The legacy and the promise}

Ramachandran has been among the global pioneers of structural molecular biology. The coiled-coil structure of collagen proposed by him has stood the test of time and has formed the basis of much of subsequent collagen 
research. The Ramachandran map, widely used in protein structural research, has almost immortalized him. He has made seminal contributions to all aspects of biomolecular conformation. Ramachandran illuminated the theoretical foundations of crystallography through his work on Fourier transforms. His approach to the use of anomalous dispersion for phase determination combined theoretical insights and practical utility. It is now three and a half decades since Ramachandran stopped active research. Yet he remains an active presence in current scientific literature.

Ramachandran demonstrated that, with imagination and ingenuity, world-class research can be done even when located in less-endowed neighbourhoods. He is considered by many as the most distinguished scientist to have worked in independent India. Generations of scientists in India and, indeed, some abroad, have been inspired by his example. This inspiration, in no small measure, contributed to the further development of structural biology in the country. After a pause, research in computational biology and bioinformatics is now in a resurgent phase. Ramachandran was keen on initiating macromolecular crystallography in India, but available resources were not adequate when he was active. Subsequently, macromolecular crystallography grew into a major research area in the country, fittingly pioneered by a research school put together by him. Ramachandran contributed to the initiation of biological NMR studies in India. Macromolecular NMR investigations are now gathering momentum in the country. While Ramachandran and his colleagues concentrated on computational and theoretical approaches, structural biology in India today encompasses a wide spectrum involving experimental as well as computational investigations. It would not be perhaps too long before contributions with impact similar to those made by Ramachandran, begin to emanate from India again.

\section{Note}

1. Only selected representative publications during the period when Ramachandran was active and the immediate aftermath are cited in the text. Partial information on subsequent publications can be obtained from http://mbu.iisc.ernet.in/ mvlab/history.html

1. Ramachandran, G. N. and Kartha, G., Nature, 1954, 174, 269.

2. Ramachandran, G. N. and Katha, G., Nature, 1955, 176, 593.

3. Ramachandran, G. N., Sasisekharan, V. and Ramakrishnan, C., J. Mol. Biol., 1963, 7, 95.

4. Ramachandran, G. N. and Sasisekharan, V., Adv. Prot. Chem., 1968, 23, 283

5. Ramachandran, G. N. and Ramakrishnan, C., Biochim. Biophys. Acta, 1962, 63, 307.

6. Ramachandran, G. N., Sasisekharan, V. and Ramakrishnan, C., Biochim. Biophys. Acta, 1966, 112, 168.

7. Chidmabaram, R., Balasubramaniam, R. and Ramachandran, G. N., Biochim. Biophys. Acta, 1970, 221, 196.
8. Ramachandran, G. N. and Raman, S., Curr. Sci., 1956, 25, 348.

9. Parthasarathy, S. and Ramachandran, G. N., Science, 1965, 150, 212.

10. Srinivasan, R. and Ramachandran, G. N., Nature, 1963, 200, 1090.

11. Parthasarathy, S. and Ramachandran, G. N., Acta Crystallogr., 1966, 21, 163.

12. Ramachandran, G. N. and Srinivasan, R., Nature, 1961, 190, 159.

13. Srinivasan, R. and Ramachandran, G. N., Fourier methods in crystallography. In Wiley Monographs in Crystallography (ed. Bueger, M. J.), Wiley Interscience, New York, 1971.

14. Ramachandran, G. N. and Lakshminarayanan, A. V., Proc. Natl. Acad. Sci., USA, 1971, 68, 2236.

15. Ramachandran, G. N. and Kolaskar, A. S., Biochim. Biophys. Acta, 1973, 303, 385.

16. Chandrasekharan, R., Lakshminarayanan, A. V., Pandya, U. V. and Ramachandran, G. N., Biochim. Biophys. Acta, 1973, 303, 14.

17. Ramachandran, G. N., Bansal, M. and Bhatnagar, R. S., Biochim. Biophys. Acta, 1973, 322, 166.

18. Sasisekharan, V. and Pattabiraman, N., Curr. Sci., 1976, 45, 779.

19. Sasisekharan, V. and Pattabiraman, N., Nature, 1978, 275, 159.

20. Gupta, G., Bansal, M. and Sasisekharan, V., Proc. Natl. Acad. Sci., USA, 1980, 77, 6486.

21. Conrad, M., Brahmachari, S. K. and Sasisekharan, V., Biosystems, 1986, 19, 123.

22. Ramesh, N., Shouche, Y. S. and Brahmachari, S. K., J. Mol. Biol., 1986, 190, 635 .

23. Jayaraman, S. and Yathindra, N., Biochem. Biophys. Res. Commun., 1980, 97, 1407.

24. Malathi, R. and Yathindra, N., J. Biomol. Strut. Dyn., 1985, 3, 127.

25. Bhattacharya, D. and Bansal, M., J. Biomol. Strut. Dyn., 1987, 4, 1027.

26. Bhattacharya, D. and Bansal, M., J. Biomol. Strut. Dyn., 1988, 6, 93.

27. Yathindra, N. and Rao, V. S. R., J. Polym. Sci. Part A-2, 1972, 10, 1369.

28. Nagarajan, M. and Rao, V. S. R., Biopolymers, 1979, 18, 1407.

29. Biswas, M., Chandra Sekharudu, Y. and Rao, V. S. R., Carbohydr. Res., 1987, 160, 151.

30. Ramakrishnan, C., Ramnarayanan, K. and Manjula, G., Int. J. Peptide Protein Res., 1987, 24, 433.

31. Mitra, J. and Ramakrishnan, C., Int. J. Peptide Protein Res., 1981, 4, 401 .

32. Srinivasan, R., Balasubramanian, R. and Rajan, S. S., J. Mol. Biol., 1975, 98, 739.

33. Srinivasan, R., Balasubramanian, R. and Rajan, S. S., Science, 1976, 194, 720.

34. Bhat, T. N., Sasisekharan, V. and Vijayan, M., Int. J. Peptide Protein Res., 1979, 13, 170

35. Soman, K. V. and Ramakrishnan, C., J. Mol. Biol., 1983, 170, 1045.

36. Kolaskar, A. S. and Ramabrahman, V., Int. J. Peptide Protein Res., 1983, 22, 83-91.

37. Bhaskaran, R. and Ponnuswamy, P. K., Int. J. Peptide Protein Res., 1984, 24, 168.

38. Bhaduri, D. and Saha, N. N., J. Cryst. Mol. Struct., 1979, 9, 311.

39. Chidambaram, R., Int. J. Quantum Chem., 1981, 20, 449.

40. Sequiera, A., Ramanadham, M., Rajagopal, H. and Padmababhan, V. M., Acta Crystallogr., 1981, 337, 1839.

41. Lalitha, V., Murali, R. and Subramanian, K., Int. J. Peptide Protein Res., 1986, 27, 472.

42. Karle, I. L., Flippen-Anderson, J., Uma, K. and Balaram, P., Proc. Natl. Acad. Sci., USA, 1988, 85, 299.

43. Narula, P., Patel, H. C., Singh, T. P., Chauhan, V. S. and Sharma, A. K., Biopymers, 1988, 27, 1595.

44. Vijayan, M., Prog. Biophys. Mol. Biol., 1988, 52, 71.

45. Viswamitra, M. A. et al., Nature, 1981, 289, 817. 
46. Devarajan, S., Nair, C. M. K., Easwaran, K. R. K. and Vijayan, M., Nature, 1980, 286, 640.

47. Francis, A. K., Iqbal, M., Balaram, P. and Vijayan, M., Biopolymers, 1983, 22, 1499.

48. Singh, T. P. and Vijayan, M., J. Chem. Soc., Perkin II, 1977, 693.

49. Chatterjee, C., Dattagupta, J. K. and Saha, N. N., Acta Crystal$\log r . B, 1981,37,1835$.

50. Patel, H. C. and Singh, T. P., Acta Crystallogr. Sect. C, 1987, 43, 844.

51. Kumar, M., Hosur, R. V., Roy, K. B., Mules, H. T. and Govil, G., Biochemistry, 1985, 24, 7703.

52. Shastri, B. P., Sankaran, M. B. and Eswaran, K. R. K., Biochemistry, 1987, 26, 4930.

53. Chandrasekharan, K., Das, M. K., Kumar, A. and Balaram, P., Int. J. Peptide Protein Res., 1988, 32, 167.

54. Salunke, D. M., Islam Khan, M., Surolia, A. and Vijayan, M., J. Mol. Biol., 1982, 154, 177.

55. Salunke, D. M., Veerapandian, B., Kodandapani, R. and Vijayan, M., Acta Crystallogr. Sect. B, 1985, 41, 431.

56. Salunke, D. M., Swamy, M. J., Islam Khan, M., Mande, S. C., Surolia, A. and Vijayan, M., J. Biol. Chem., 1985, 260, 13576.
57. Kumar, V., Sankaran, K. and Kannan, K. K., J. Mol. Biol., 1986, $190,129$.

58. Munshi, S. K., Hiremath, C. N., Savithri, H. S. and Murthy, M. R. N., Acta Crystallogr. Sect. B, 1987, 43, 376.

59. Dhanaraj, V., Patanjali, S. R., Surolia, A. and Vijayan, M., J. Mol. Biol., 1988, 203, 1135.

60. Bansal, M., Ph D thesis, Indian Institute of Science, Bangalore, 1977.

61. DeLano, W. L., 2002; http://www.pymol.org

62. Ramakrishnan, C., Resonance, October 2001, 48-56.

63. Vijayan, M. and Johnson, L. N., Biogr. Mem. Fellows R. Soc., $2005, \mathbf{5 1}, 367$.

ACKNOWLEDGEMENTS. I thank K. V. Abhinav and Pankaja C. for help in preparing the figures and the text of the manuscript respectively and Manju Bansal for discussions.

doi: $10.18520 / \mathrm{cs} / \mathrm{v} 110 / \mathrm{i} 4 / 535-542$ 